\title{
ASPECTOS QUALITATIVOS DA FORMA URBANA E USO DO ESPAÇO PÚBLICO \\ Análise de Praças do Bairro Centro de Teresina (PI)
}

\section{QUALITATIVE ASPECTS AND USE OF PUBLIC SPACES Analysis of Squares in Teresina (PI) Downtown}

\author{
A. José Mário Pacheco Júnior \\ PPG FAU, Faculdade de Arquitetura e Urbanismo; Universidade de Brasília, Brasil \\ mariopachecoarquitetura@gmail.com \\ B. Pedro Marcelo de Sousa Ferreira \\ Núcleo de Teoria História da Arte e Arquitetura - NTHAARQ, Centro de Tecnologia, \\ Universidade Federal do Piauí, Brasil \\ pedromarcelo.sf@gmail.com
}

\section{Antônio Rubens Fernandes Chaves}

PPGGEO, Centro de Ciências Humanas e Letras, Universidade Federal do Piauí, Brasil rubenschaves@outlook.com

\section{RESUMO}

Este trabalho analisa duas praças do Centro da cidade de Teresina (PI): Praça João Luís Ferreira e Praça Da Costa e Silva. São observados aspectos físico-ambientais que possibilitam inferir a qualidade ambiental urbana (Santos; Hardt, 2013) destes espaços e as suas implicações para o uso pela população. A fundamentação teórica apresenta os conceitos de sustentabilidade e qualidade ambiental urbana, espaços livres, áreas verdes urbanas e apropriação do espaço. Foram selecionados para o estudo os indicadores: arborização, sombreamento, gabaritos, dimensões do espaço, mobiliário urbano, uso do solo, acessos e fechamentos. Objetiva-se compreender em que medida os aspectos observados interferem na qualidade e na apropriação dos espaços. A análise demonstra que a apropriação possui maior relação com aspectos de uso do solo em detrimento aos de conforto ambiental. O trabalho contribui à discussão de como aspectos físico-ambientais interferem na qualidade de espaços públicos e a sua resultante à vitalidade das cidades.

Palavras-chave: uso do espaço público; forma urbana; indicadores de qualidade ambiental urbana; Teresina (PI).

Linha de Investigação: 1: Cidade e projeto.

Tópico: Projeto urbano e espaço público. 


\title{
XII SÃOPAULO15 $17 \cdot$ LISBOA $25 \sim 26$ JUN 2020
}

Seminário Internacional de Investigação em Urbanismo

\begin{abstract}
This paper analyses two squares in Teresina (PI) downtown: João Luís Ferreira Square and Da Costa e Silva Square. There are examined physical-environmental aspects that allow infer about environmental urban quality (SANTOS; HARDT, 2013) of the squares and the implications of it the use of these spaces by population. The theoretical basis presents concepts of urban sustainability and environmental quality, open spaces, green urban areas, and spatial appropriation. There were selected to this study the indicators: afforestation, shadows, building heights, spatial dimensions, urban furniture, land use activities, access, and barriers. The study aims to comprehend how the examined aspects contribute to quality and appropriation of the squares. The analysis demonstrates that the appropriation of public spaces is more related to aspects of land use in order to environmental aspects. The paper contributes to discuss how physical-environmental aspects interfere public spaces quality and to the resulting vitality of cities.
\end{abstract}

Keywords: use of public spaces; urban form; environmental urban quality indicators; Teresina (PI).

Research line: 1 City and design.

Topic: Urban design and public space.

\section{Introdução}

Grande parte dos aglomerados urbanos sofre com adversidades provenientes do não planejamento ou do planejamento defasado do uso e ocupação do solo urbano (Rattner, 2009). As cidades mantêm processos e dinâmicas em que modelos de uso e ocupação do solo ineficientes consomem o espaço, afetando o meio ambiente, promovendo elevado consumo de matérias primas, gastos de energia e geração de resíduos e precarização de porções urbanas em detrimento de outras (Martins; Cândido, 2013). Uma das consequências negativas é a depreciação dos espaços de convivência em áreas urbanas centrais, em função do não planejamento integrado entre desenho e uso do solo urbano.

A sustentabilidade urbana procura reverter este cenário, orientando a produção planejada do espaço urbano de modo economicamente viável, socialmente aceitável, ambientalmente adequado e tecnicamente possível. Porém, cidades possuem processos e dinâmicas particulares, onde a sustentabilidade urbana deve promover essas transformações atendendo a contextos urbanos distintos (Swyngedouw, 2009).

Acselrad (2009) afirma que a Qualidade de Vida é um dos aspectos essenciais para o alcance da sustentabilidade urbana, enquanto para Santos e Hardt (2013) a qualidade de vida está diretamente ligada à qualidade ambiental urbana, pois o meio ambiente urbano determina o aspecto de qualidade da vida nas cidades. Assim, cidades que apresentam qualidade ambiental urbana possuem potencial para alcançar sua sustentabilidade.

A provisão de qualidade ambiental à cidade relaciona-se com diversos aspectos da forma urbana - a preservação do espólio ambiental natural, o desempenho de serviços ambientais por infraestruturas verdes e cinzas, a presença de espaços propícios e convidativos ao convívio social, entre outros. Espaços livres públicos de convivência - praças, jardins públicos, parques - articulados no tecido urbano e atendendo a princípios de qualidade ambiental urbana, são excelentes formas de promover essa qualidade. 


\section{SÃOPAULO15 17 LISBOA $25 \sim 26$ JUN 2020

Ante o exposto, o presente artigo desenvolverá um estudo comparativo entre dois espaços livres públicos de convivência da zona urbana central da cidade de Teresina, capital do Piauí - as praças "João Luiz Ferreira" e "Da Costa e Silva". Serão apresentados conceitos correlatos à análise pretendida, como Qualidade Ambiental Urbana, Espaços Livres, Áreas Verdes Urbanas e Apropriação do Espaço Urbano. Utilizando indicadores de aferição qualitativa da qualidade ambiental urbana, procurar-se-á verificar como estes indicadores se encontram no espaço, contrapondo-os à apropriação observada nas praças analisadas, buscando compreender em que medida estes aspectos de análise a influenciam e a relação da apropriação observada com a qualidade ambiental urbana.

\section{Qualidade do Espaço Livre Público: conceitos relacionados}

\subsection{Sustentabilidade Urbana e Qualidade Ambiental Urbana}

A significação de "sustentabilidade urbana" permanece em constante processo de estruturação (Braga, 2006; Martins e Cândido, 2013). Na tentativa de mensurar e analisá-la, Acselrad (2009) cria três matrizes de estudo que permitem a compreensão das particularidades de cada meio urbano e da sustentabilidade urbana. A primeira matriz é a "representação técnico-material das cidades", com foco nas bases técnicas da cidade a partir dos modelos de "racionalidade eco-energética" ou de "metabolismo urbano", que trata do consumo e descarga de energia e do ajustamento dos fluxos de matéria. A segunda matriz trata da "cidade como um espaço da qualidade de vida" e se baseia nos modelos de pureza, cidadania e patrimônio, focando no desempenho social do espaço urbano e seu viés sustentável, estudando a sustentabilidade partindo dos diálogos sociopolíticos que implicam em cidadania, e de possibilidades quanto ao meio possuir e proporcionar uma identidade urbana aos moradores. A terceira matriz aborda "a cidade como espaço de legitimação das políticas urbanas", na qual a sustentabilidade urbana refere-se à reprodução da legitimidade das políticas urbanas (Acselrad, 2009).

Evidencia-se que, para planejar um conjunto urbano buscando a sustentabilidade, é de fundamental importância observar o contexto existente para, então, procurar atender às particularidades do meio, momento em que as matrizes discursivas de Acselrad assumem papel essencial.

Santos e Hardt (2013) afirmam que o ambiente urbano é composto por elementos naturais (clima, ar, água, solo, fauna e flora) e antrópicos, onde a qualidade ambiental urbana seria "a somatória da qualidade dos ambientes e cenários naturais e antrópicos da cidade" (Santos; Hardt, 2013: 151), sendo ela imprescindível para a provisão de qualidade de vida. A qualidade ambiental urbana seria o estado de atendimento aos indivíduos, em níveis adequados, pelos elementos antrópicos do espaço urbano - aspectos territoriais (características de uso do solo, infraestrutura e serviços urbanos) e socioeconômicos (planejamento, gestão e participação igualitária da sociedade nos processos urbanos).

\subsection{Espaços Livres e Áreas Verdes Urbanas}

Tratando dos elementos territoriais, espaço livre é todo espaço não edificado, esteja ele qualificado ou não (Magnoli, 2006). Este espaço pode se encontrar aberto, completamente integrado ao entorno circundante, ou compreendido entre barreiras físicas ou conjuntos de edifícios. A ideia de espaço livre compreende desde avenidas em um centro urbano ou faixas de areia em praias, até espaços parcial ou totalmente vegetados, independentemente de seu uso, desde que ausente de edificações, como campos de futebol, jardins, praças ou parques (Magnoli, 2006; Miranda, 2015). Os espaços livres são palco do cotidiano citadino, do confronto de interesses e da coletividade, articulando percursos e alocando sistemas urbanos, tais como o viário e o de 


\section{SÃOPAULO15 $17 \cdot$ LISBOA $25 \sim 26$ JUN 2020}

drenagem (Rodrigues, 1986; Schlee et al., 2009; Macedo et al., 2012), o que corrobora sua importância frente ao planejamento das cidades.

Há a necessidade de se pensar os espaços livres não como resíduos da ocupação urbana, formal ou não, mas como estruturadores do desenvolvimento e ordenamento territorial, considerando seu caráter sistêmico que, como observa Tardin (2008: 17), apresenta "potencial para reestruturar o território urbano e ordenar uma possível futura ocupação". Os espaços livres se tornam capazes de qualificar a paisagem, definirem o parcelamento, o uso e a ocupação do solo, tornando-se estruturadores da dinâmica urbana.

Cavalheiro et al. (1999) definem as áreas verdes como parte do espaço livre, tendo como componente principal as árvores que, segundo Mascaró e Mascaró (2002), são elementos fundamentais da infraestrutura urbana e do paisagismo para questões como embelezamento, orientação, identidade e delimitação visual de espaços. Lodoba e Angelis (2005) observam que as árvores provisionam serviços ecossistêmicos e parte da benesse psicológica das áreas verdes, diminuindo o estresse comum às áreas urbanas. A arborização se consolida como qualificadora da paisagem urbana, em vista dos impactos visuais, climáticos, sociais, emocionais supracitados. Entretanto, a associação de áreas verdes e arborização não garante, sozinha, a qualidade ambiental a uma área, mas é um início ao processo para o alcance dessa excelência (Lima; Amorim, 2006).

\subsection{Apropriação do Espaço Urbano}

Espaço urbano é o "espaço físico, transformado por agentes sociais, que o produzem com finalidades colocadas pelos grupos que detêm os meios de produção e a gerência dos lugares" (Kohlsdorf, 1996: 21), ou "o espaço transformado por ações humanas" (ibid: 25). Kohlsdorf (1996: 26) afirma que a apropriação do espaço urbano "não se trata, portanto, de um produto neutro e passivo, mas capaz de favorecer ou inibir o desenvolvimento das ações humanas e a realização de anseios pessoais".

A apropriação do espaço urbano decorre do uso do espaço para as mais variadas atividades - estacionárias ou transitórias, ou para funções de moradia, lazer, trabalho, entre outras - e se torna essencial para que o espaço apresente práticas sociais. Assim, a configuração do espaço urbano (ex.: aberturas, fechamentos, limites, permeabilidades) tem influência direta sobre as práticas sociais, ou seja, na apropriação do espaço. A configuração do espaço, a diversidade de usos e tipologias edilícias estão entre aspectos territoriais integrantes da qualidade ambiental urbana.

\section{A Construção da Análise e os Indicadores de Qualidade Ambiental Urbana}

Os indicadores de qualidade ambiental urbana são aspectos da forma urbana - ambientais e de desenho urbano - pelos quais se busca mensurar, categorizar ou, mais precisamente, avaliar o espaço urbano e, quando pertinente, suas implicações para o convívio social. Os indicadores se referem a características, dimensões e atividades presentes ou desenvolvidas no espaço urbano que permitem, a partir de reflexão quanto às implicações destes aspectos, avaliar em que medida o espaço dispõe do que é compreendido como qualidade ambiental urbana.

Uma vez que cada contexto urbano dispõe de aspectos físico-ambientais e socioeconômicos particulares, a escolha e interpretação dos indicadores selecionados para avaliar a qualidade ambiental urbana devem se ater às particularidades do espaço urbano em questão (Krafta, 2014). Por exemplo, a escolha e a 


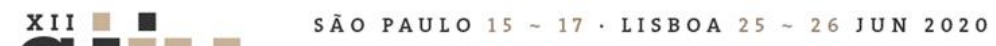

interpretação de indicadores de qualidade ambiental urbana em espaços públicos de uma cidade no Nordeste do país, muito provavelmente, serão distintas se feitas para a avaliação de cidades da região Sul. Características geográficas, como clima e relevo, ou questões culturais que influem no uso do espaço, por exemplo, devem ser sempre consideradas no desenvolvimento de estudos onde a aplicação de indicadores relativos à qualidade ambiental urbana é utilizada.

O emprego de indicadores de qualidade ambiental urbana para a avaliação de espaços é pertinente para discutir o alcance dessa qualidade, porque permite já analisar o que seria uma condição qualitativa. A interpretação dos indicadores é feita explicando quais as condições ideais desse espaço para que ele apresente a qualidade buscada (Sewell, 1978).

O presente trabalho foi desenvolvido a partir da análise in loco de indicadores de qualidade ambiental urbana. A seleção de indicadores foi realizada a partir de Santos e Hardt (2013), selecionando aspectos espaciais que possibilitassem uma leitura das qualidades ambiental e urbana. A escolha dos indicadores utilizados no trabalho se deu após visitas às praças que se pretendia analisar, observando as características de ambas e as possibilidades de análise espacial cabíveis. Após escolhidos os indicadores, foram observadas características ambientais e do desenho das praças, investigando desde a presença ao estado de conservação.

Os indicadores de qualidade ambiental urbana selecionados se relacionam às esferas natural e antrópica, se subdividem em parâmetros (categorias de leitura utilizadas na análise) e são apresentados na Tabela 1.

\begin{tabular}{|c|c|c|}
\hline Tipo de Indicador & $\begin{array}{l}\text { Parâmetro } \\
\text { analisado }\end{array}$ & Indicador \\
\hline Natural & Vegetação & Arborização \\
\hline Natural & $\begin{array}{l}\text { Barreiras à } \\
\text { insolação }\end{array}$ & Sombreamento \\
\hline Antrópico & Forma Edilícia & $\begin{array}{c}\text { Gabarito edilício do } \\
\text { entorno }\end{array}$ \\
\hline Antrópico & Desenho local & $\begin{array}{l}\text { Dimensões e } \\
\text { extensões do } \\
\text { espaço }\end{array}$ \\
\hline Antrópico & Desenho local & Mobiliário urbano \\
\hline Antrópico & Uso do solo & $\begin{array}{c}\text { Atividades } \\
\text { desenvolvidas no } \\
\text { entorno }\end{array}$ \\
\hline Antrópico & Uso do solo & $\begin{array}{c}\text { Atividades } \\
\text { comerciais } \\
\text { estacionárias }\end{array}$ \\
\hline
\end{tabular}




\section{SÃO PAULO $15 \sim 17 \cdot$ LISBOA $25 \sim 26$ JUN 2020 \\ $\begin{array}{ll}\text { Seminário Internacional de } & \text { Seminario Internacional de } \\ \text { Investigação em Urbanismo } & \text { Investigación en Urbanismo }\end{array}$}

Público Coletivo Municipal, enquanto a segunda, Praça Da Costa e Silva, se localiza na periferia da área comercial do bairro (Fig. 1 e 2).

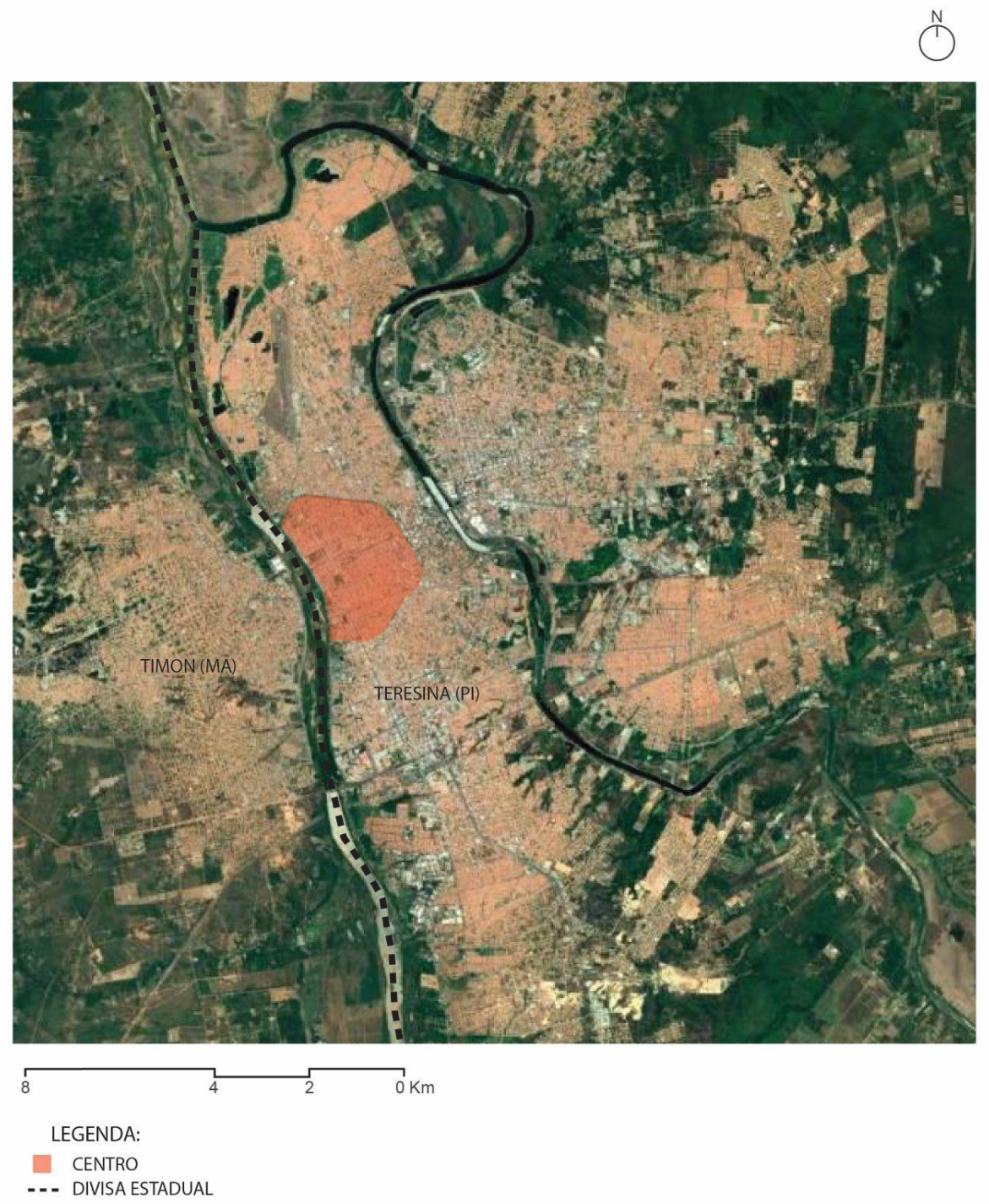

Fig. 01: Vista aérea da cidade de Teresina com a localização do bairro Centro. Fonte: Elaboração própria a partir de imagem do Google Earth Pro. 

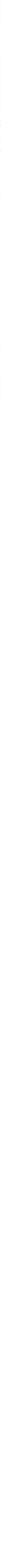

Fig. 02: Vista aérea do bairro Centro de Teresina com a localização das Praças João Luís Ferreira e Da Costa e Silva. Fonte: Elaboração própria a partir de imagem do Google Earth Pro.

Quanto aos indicadores, serão analisados os de caráter natural: arborização, sombreamento e poluição sonora; e os de caráter antrópico: gabarito do entorno, dimensões e extensões do espaço, mobiliário urbano, atividades do entorno (uso do solo), presença e conservação de rampas de acessibilidade e fechamentos.

A Praça João Luís Ferreira (Fig. 3), já prevista no plano original da cidade, ocupa um quarteirão quadrangular inteiro entre as ruas Coelho Rodrigues, David Caldas, Eliseu Martins e Sete de Setembro, mede aproximadamente $73 \mathrm{~m} \times 70 \mathrm{~m}$ e tem área aproximada de $5.976,47 \mathrm{~m}^{2}$. A praça possui uma Estação de Transbordo de Transporte Coletivo, o que já garante um fluxo de usuários neste espaço livre público. A presença de vendedores ambulantes, quiosques comerciais e pontos de táxi também atrai usuários com 


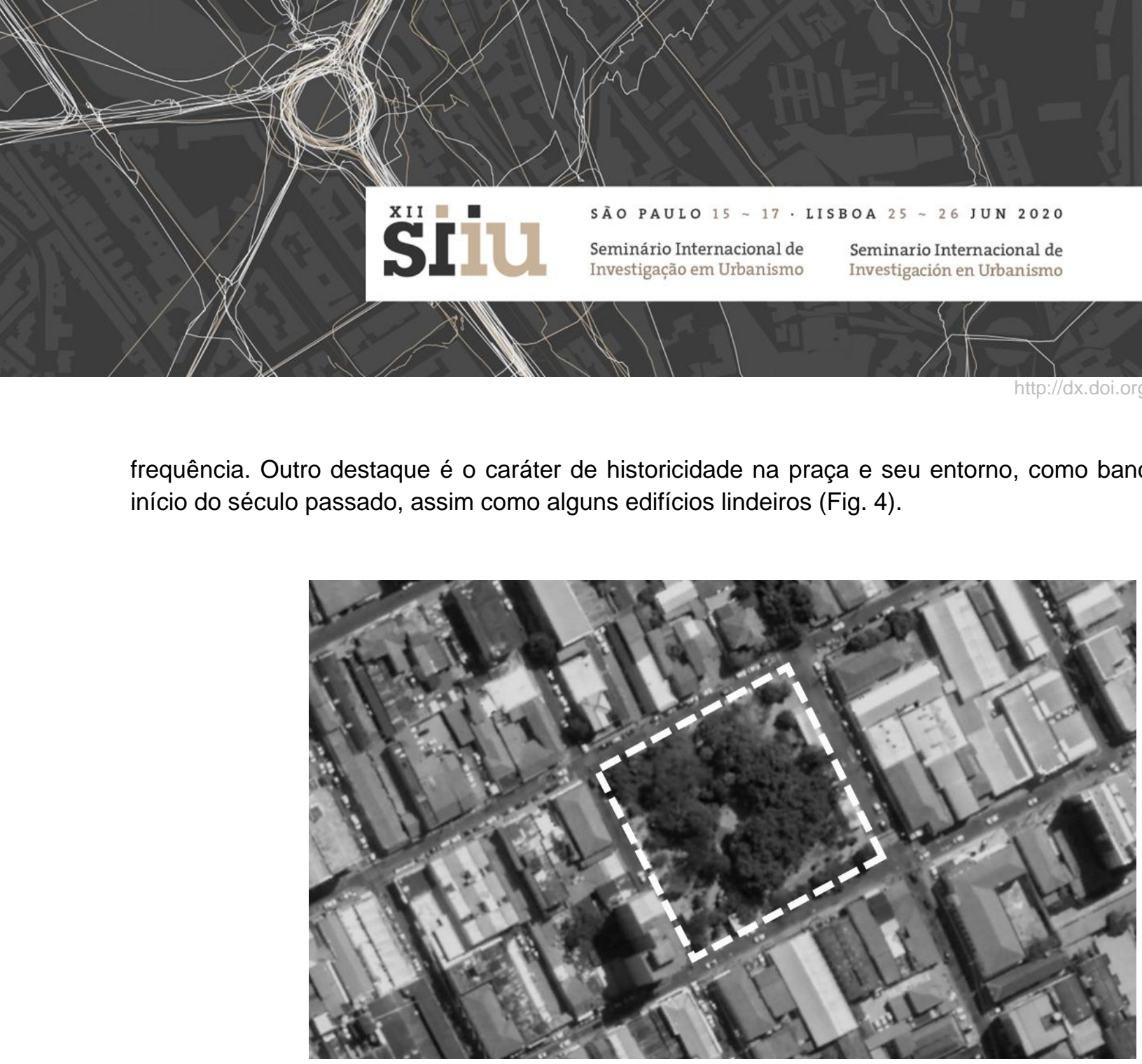

Fig. 03: Vista aérea da Praça João Luís Ferreira (tracejada em branco). Fonte: Elaboração própria a partir de imagem do Google Earth Pro.

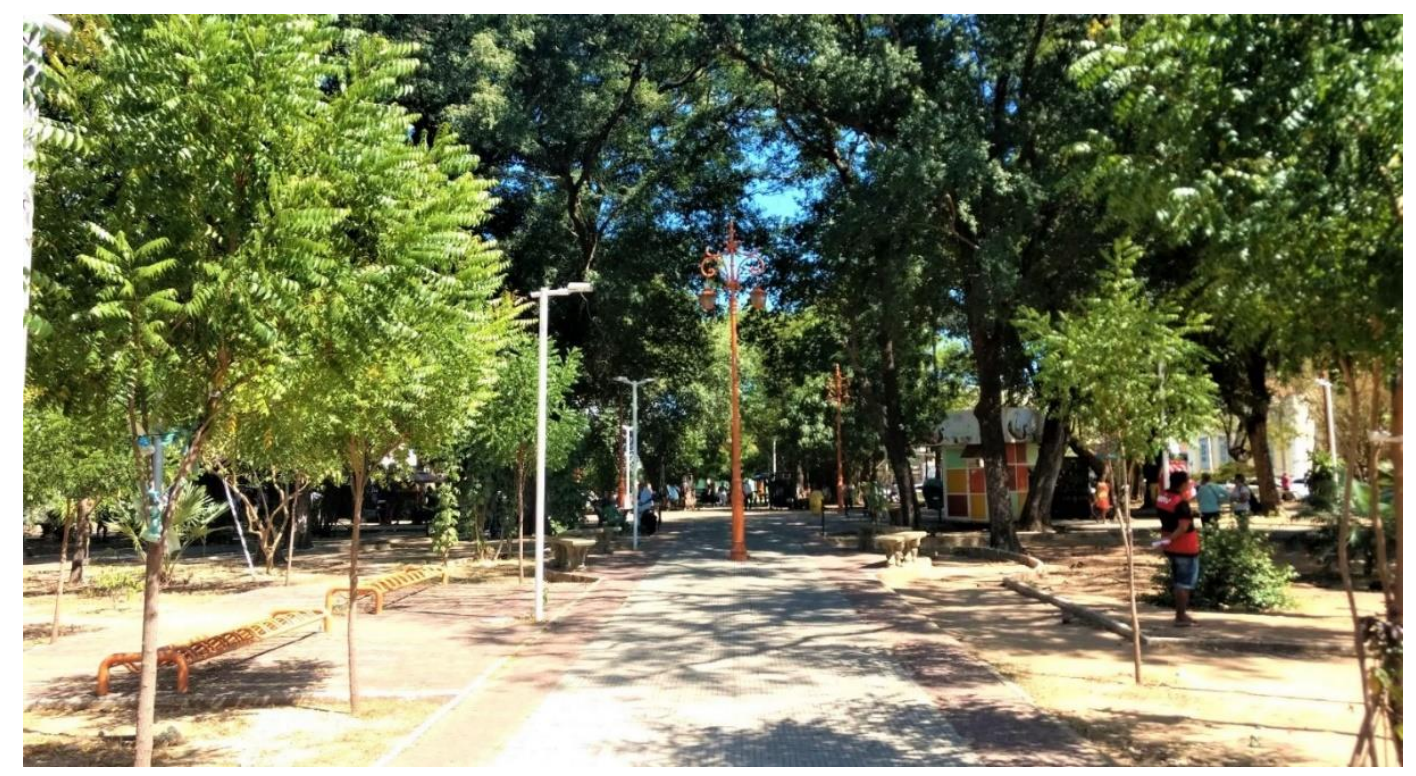

Fig. 04: Vista da Praça João Luís Ferreira. Fonte: Elaboração própria.

A Praça Da Costa e Silva (Fig. 5) está localizada entre a Avenida Maranhão, Avenida José dos Santos e Silva, Rua João Cabral e Rua Santa Luzia, ocupando um quarteirão inteiro. Com projeto paisagístico de Roberto Burle Marx, a praça se caracteriza uma obra de arte urbana (Fig. 6). Encontra-se, entretanto, 


\section{SÃOPAULO15 17 LISBOA $25 \sim 26$ JUN 2020 \\ $\begin{array}{ll}\text { Seminário Internacional de } & \text { Seminario Internacional de } \\ \text { Investigação em Urbanismo } & \text { Investigación en Urbanismo }\end{array}$}

subutilizada. Possui geometria trapezoidal, seu menor lado possui 45,5m e o maior, 252,0m, com área de $17.736,95 \mathrm{~m}^{2}$. A Fig. 7 apresenta as dimensões das praças, evidenciando características de tamanho e forma.

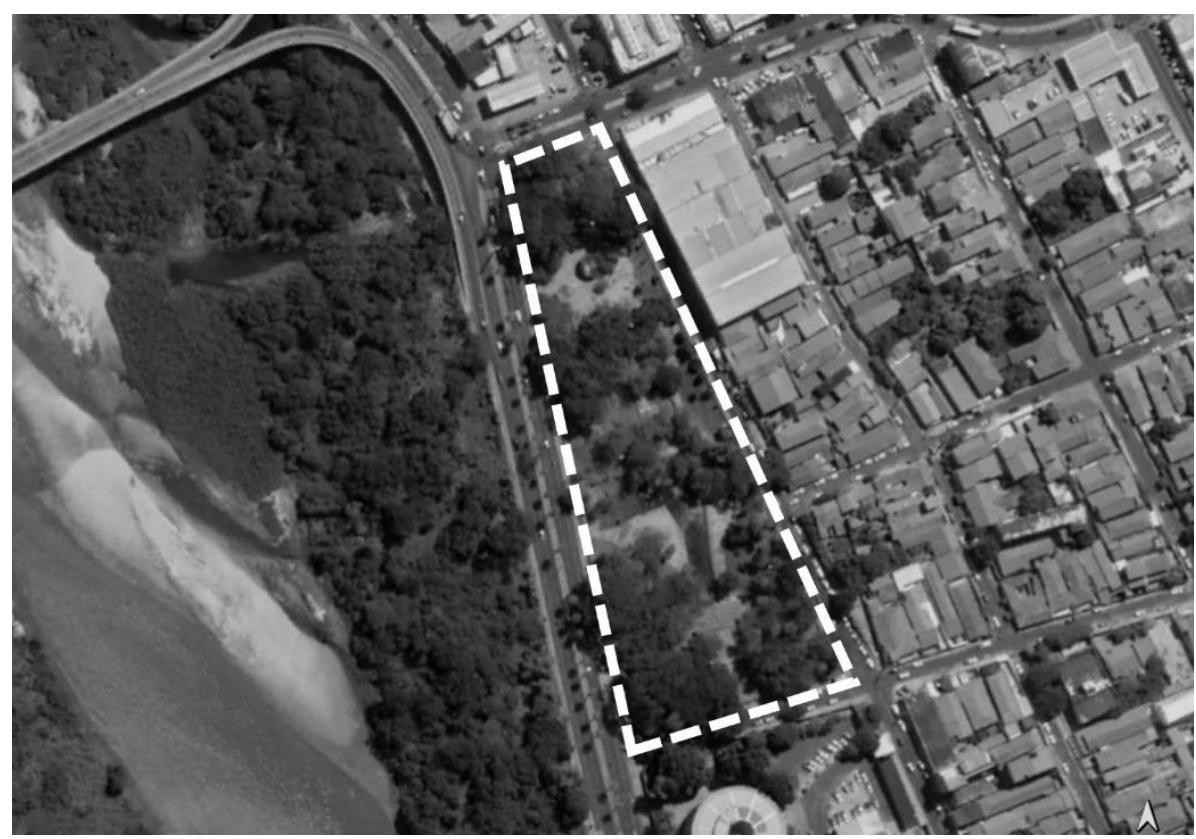

Fig. 05: Vista aérea da Praça Da Costa e Silva (tracejada em branco). Fonte: Elaboração própria a partir de imagem do Google Earth Pro.

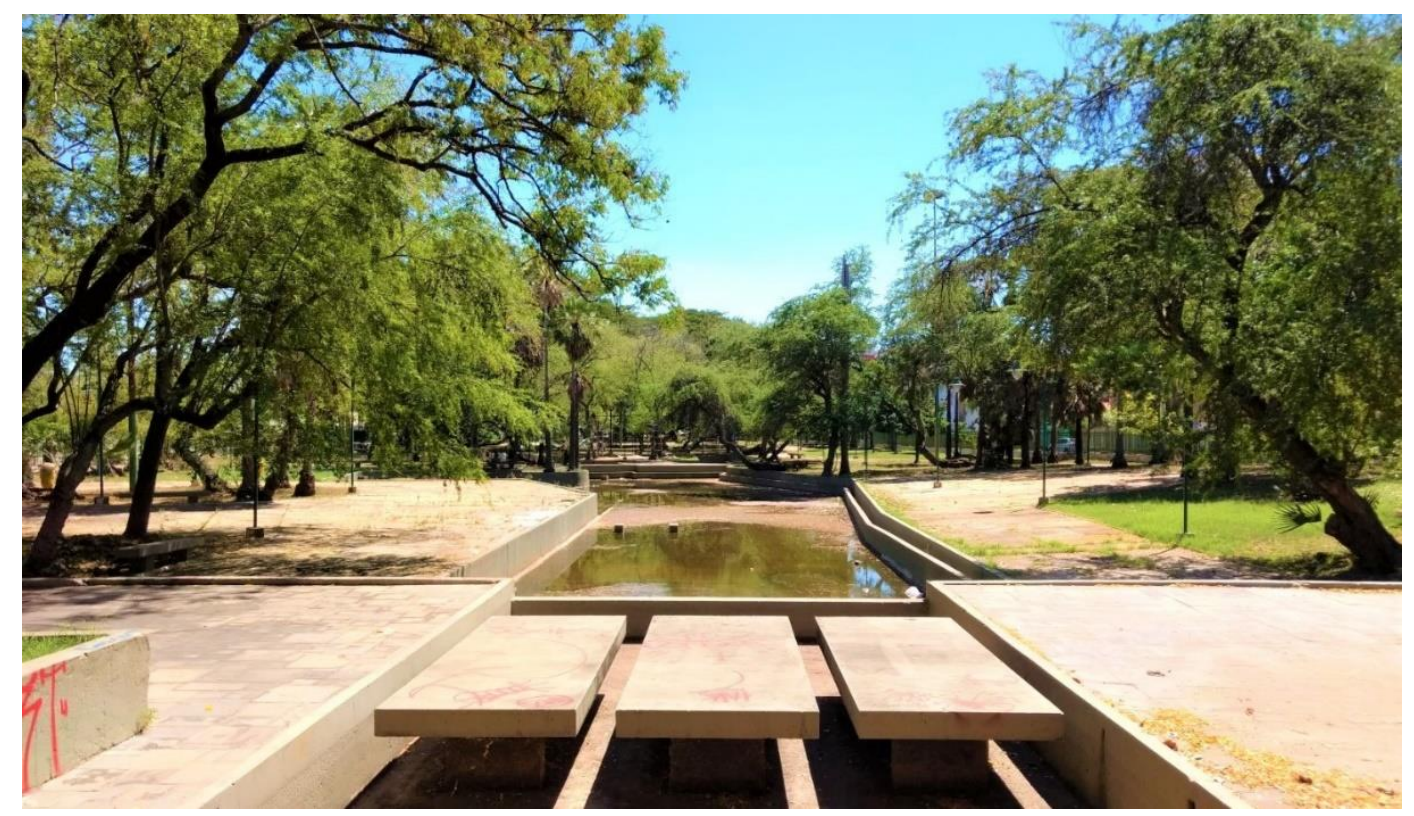

Fig. 06: Vista da Praça Da Costa e Silva. Fonte: Elaboração própria. 


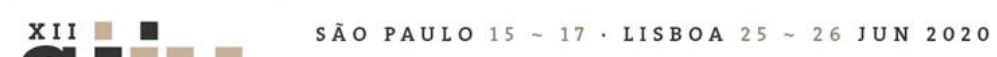

Seminário Internacional de Investigação em Urbanismo

Seminario Internacional de Investigación en Urbanismo

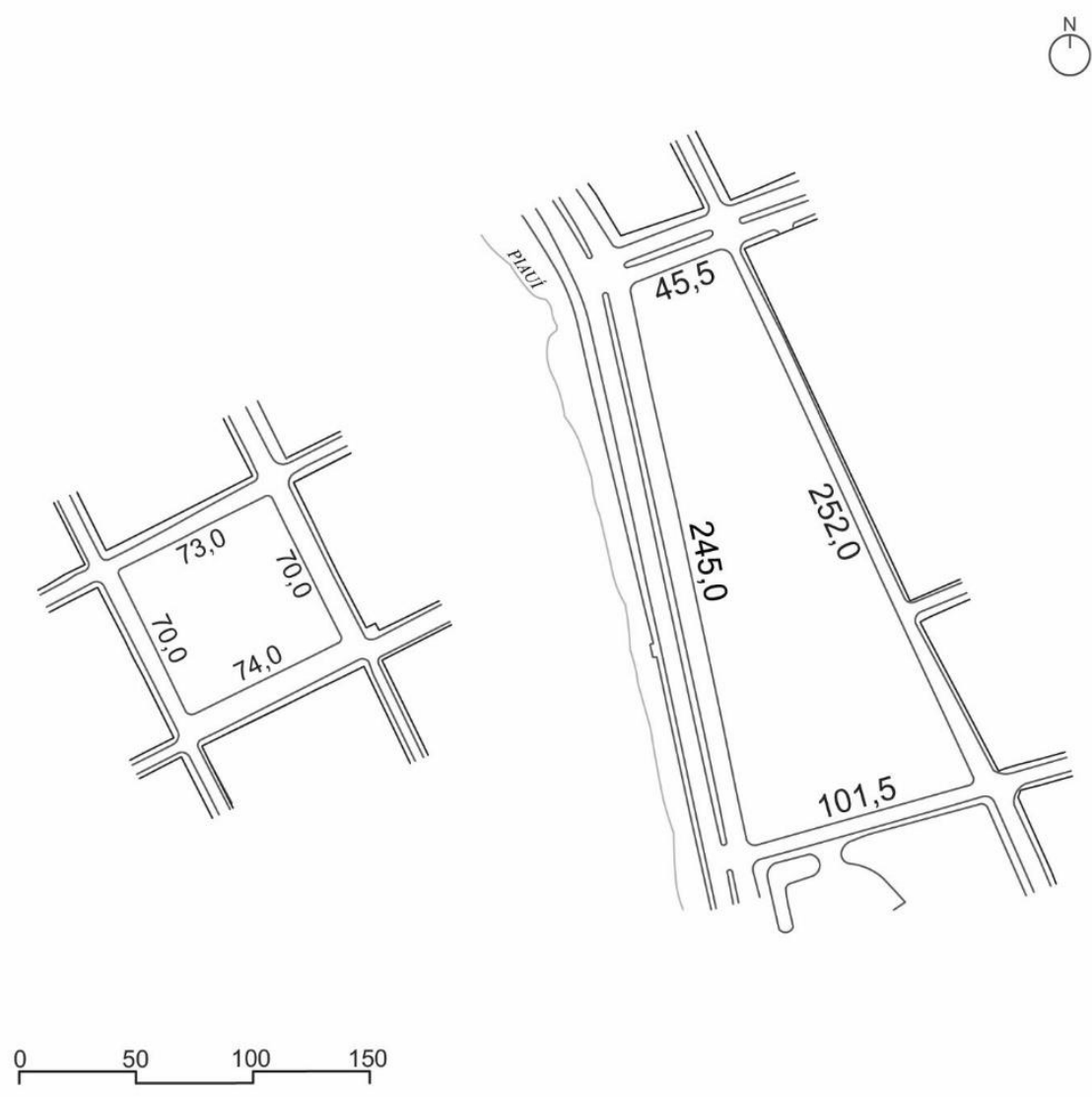

Fig. 07: Cartograma de dimensões das praças João Luís Ferreira (à esquerda) e Da Costa e Silva (à direita). Fonte: Elaboração própria.

\subsection{Interpretação dos Indicadores de Análise}

Iniciando pela análise dos indicadores naturais, as praças apresentam arborização e sombreamento distintos, decorrente das espécies arbóreas utilizadas e da disposição da arborização. Na Praça João Luís Ferreira o sombreamento é maior na área central, proporcionado, principalmente, por árvores antigas, nativas e de copas grandes. Nesta praça se observam as áreas perimetrais menos sombreadas, uma vez que as árvores locadas nestas áreas são mais jovens e espaçadas umas das outras, ainda não proporcionado efetivo sombreamento (Fig. 8). 



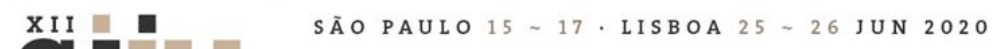

a intenso. Estes aspectos resultam numa praça com muitos ruídos, mas ainda mais calma em relação às áreas comerciais do bairro Centro - fator atribuído especialmente à arborização. Já a Praça Da Costa e Silva possui entorno imediato majoritariamente residencial, com instituições e comércios nos quarteirões próximos. Internamente, esta praça é mais silenciosa. Ruídos observados são oriundos do tráfego nas avenidas Maranhão e José dos Santos e Silva. É interessante notar que a praça apresenta microclima ameno, distinto do entorno, e poucos ruídos.

Quanto aos aspectos antrópicos, os acessos e fechamentos das praças representam uma primeira barreira ou potencial ao uso dos espaços. A Praça João Luís Ferreira não apresenta fechamentos (Fig. 9), configurando-se um espaço permeável e convidativo à passagem. O desenho dos percursos, retilíneos e que cruzam a praça axialmente em variadas as direções, também são aspectos contributivos ao alto fluxo de pedestres. Já a Praça Da Costa e Silva tem configuração distinta. É gradeada e tem desenho de percursos direcionado aos únicos quatro acessos. O fechamento, apesar da intenção de proteção, acaba por privar o espaço da interação com a cidade. Vê-se uma maior restrição de acessos e barreira por fechamentos na Praça Da Costa e Silva, opostos à permeabilidade da Praça João Luís Ferreira (Fig. 9).

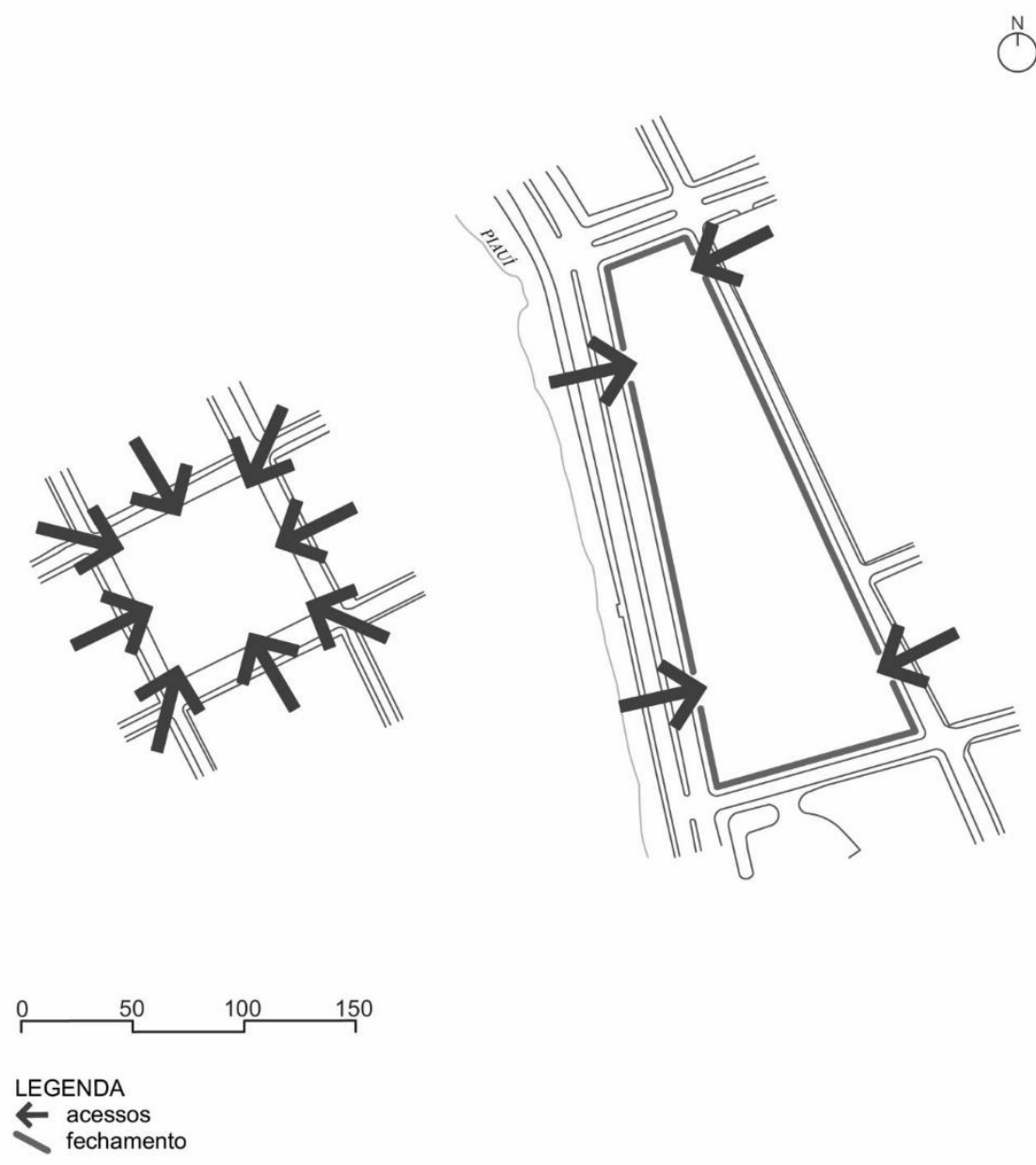

Fig. 09: Cartograma de acessos e fechamentos das praças João Luís Ferreira (à esquerda) e Da Costa e Silva (à direita). Fonte: Elaboração própria. 


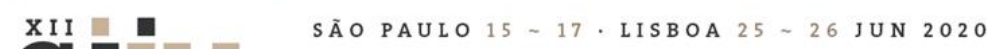

O uso do solo do entorno das praças é importante para a ocupação, sendo indispensável nesta análise em função da interrelação desse indicador com a dinâmica urbana de uma área. A natureza e a variedade de atividades de determinado local influenciam diretamente na atratividade que este local tem para pessoas. Quanto aos espaços aqui analisados, a Praça João Luís Ferreira apresenta maior variedade no uso do solo, provavelmente em decorrência de sua localização central no bairro (Fig. 10).
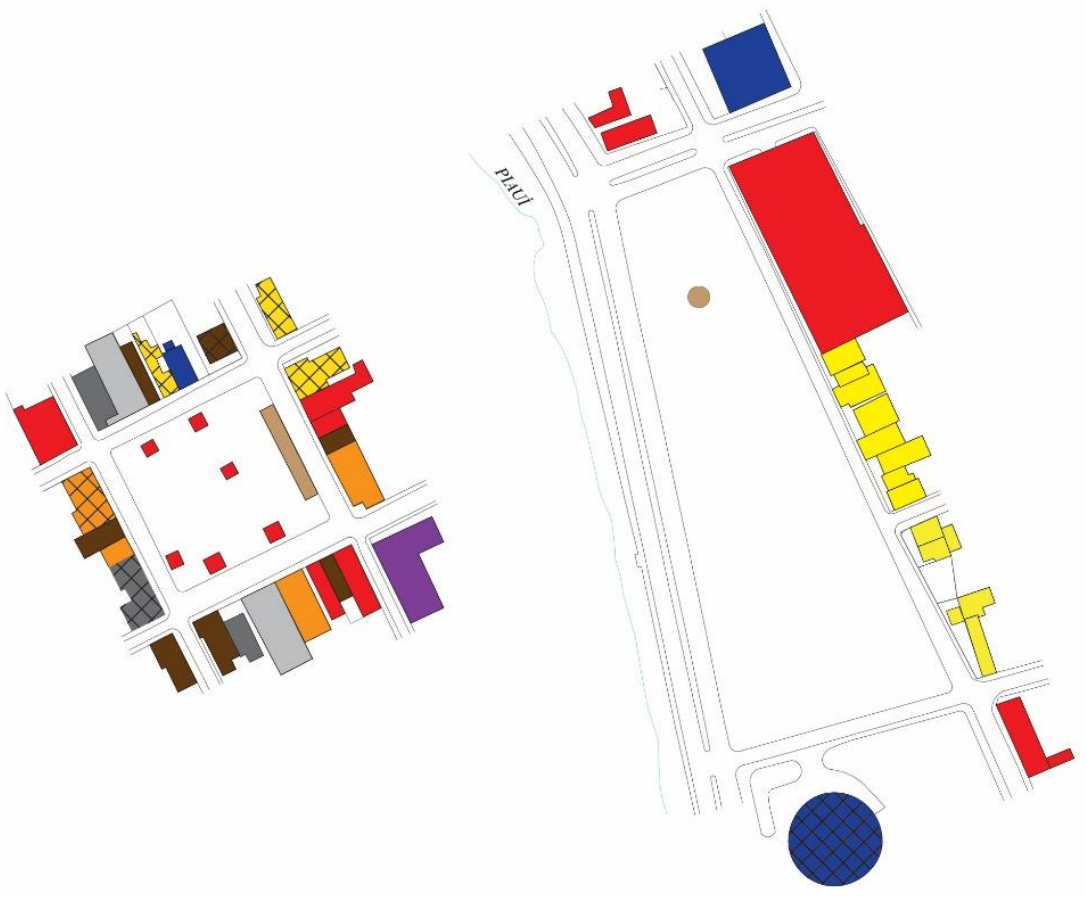

Fig. 10: Cartograma de atividades desenvolvidas no entorno das praças João Luís Ferreira (à esquerda) e Da Costa e Silva (à direita). Fonte: Elaboração própria.

Na Praça Da Costa e Silva os usos se restringem ao comercial, institucional, serviços e residencial. Apesar de certa variação, este espaço tem a peculiaridade de só apresentar edificações próximas em duas das fachadas voltadas para a praça, como observado na Fig. 10. O uso residencial é maior em quantidade de imóveis, mas não em área. Maior parte do entorno imediato à praça é institucional ou comercial, e os acessos a estes imóveis não são realizados pelas vias que circundam a Praça Da Costa e Silva, 


\section{SÃO PAULO15 17 LISBOA $25 \sim 26$ JUN 2020}

prejudicando a atratividade de pessoas ao espaço. Além disso, a fachada oeste, voltada para a Avenida Maranhão, é oposta ao um rio e, como observado, não existem edificações nesta região (Fig. 10).

Relacionado ao uso do solo, a análise dos gabaritos tem estreita relação com a densidade habitacional da área ou com o potencial de atração de trabalhadores, no caso de usos institucional, serviços e comercial. Este indicador busca compreender a relação entre adensamento edilício e a quantidade de pessoas que potencialmente utilizam o espaço.

O entorno da Praça João Luís Ferreira, por conta do cone de aproximação do aeroporto de Teresina e da predominância de prédios históricos, tem gabarito médio de dois pavimentos, excetuando o antigo prédio do Instituto Nacional de Previdência Social - INPS, de oito pavimentos, mas que, atualmente, se encontra desocupado (Fig. 11). Esse contexto influi nos usos do entorno, pois inviabiliza a implementação de usos que demandem maior área edificável e, consequentemente, atraiam mais pessoas, tendo implicação direta sobre a apropriação do espaço.

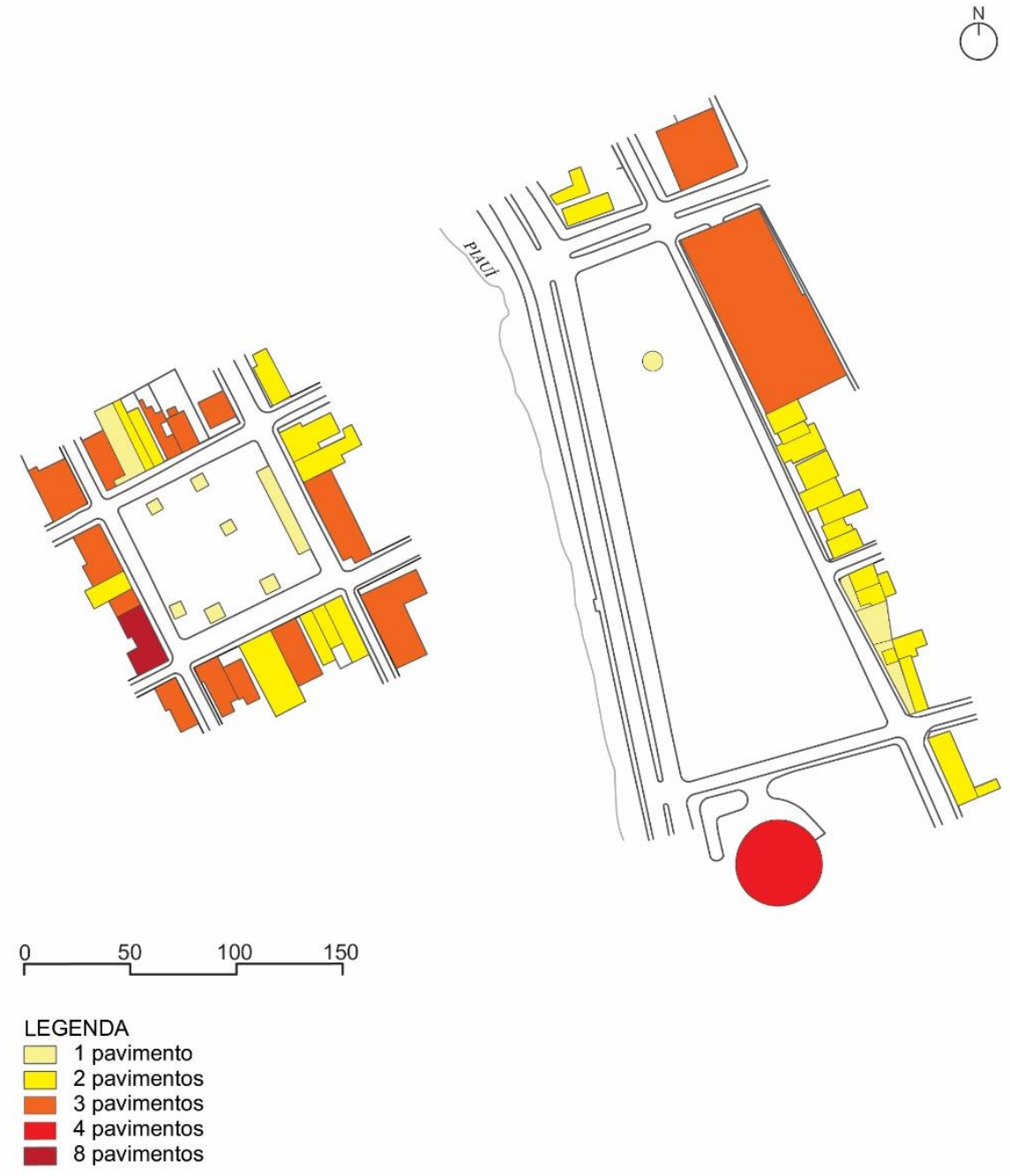

Fig. 11: Cartograma de gabaritos do entorno das praças João Luís Ferreira (à esquerda) e Da Costa e Silva (à direita). Fonte: Elaboração própria. 


\section{SÃOPAULO15 17 LISBOA $25 \sim 26$ JUN 2020}

Na Praça Da Costa e Silva os gabaritos em média são baixos. O gabarito, na grande maioria do entorno, é térreo, exceto pelo prédio da Companhia Energética do Piauí - Cepisa, ao Sul da praça, de quatro pavimentos, e dois edifícios, um comercial, outro institucional, estes três com dois pavimentos cada (Fig. 11).

A presença de mobiliário urbano, sua disposição e estado de conservação são bastante contributivos à ocupação de um espaço livre urbano. Em ambas as praças, o mobiliário observado, em sua maioria, se encontra em bom estado de conservação, é variado e está disposto por toda a área da praça (Fig. 12). Ambas as praças têm paradas de ônibus, ainda que a Praça João Luís Ferreira apresente uma estação de transporte coletivo e a Praça Da Costa e Silva, somente abrigos de passageiros. Possuem sinalização e iluminação satisfatórias em conservação e disposição dos objetos no espaço, além de bancos e lixeiras em quantidade razoável e bem dispostas; os bancos, em áreas sombreadas e as lixeiras, próximas dos acessos. Neste indicador, a Praça João Luís Ferreira apresenta, a mais, bancas de jornal e abrigos (cobertas) para taxistas.
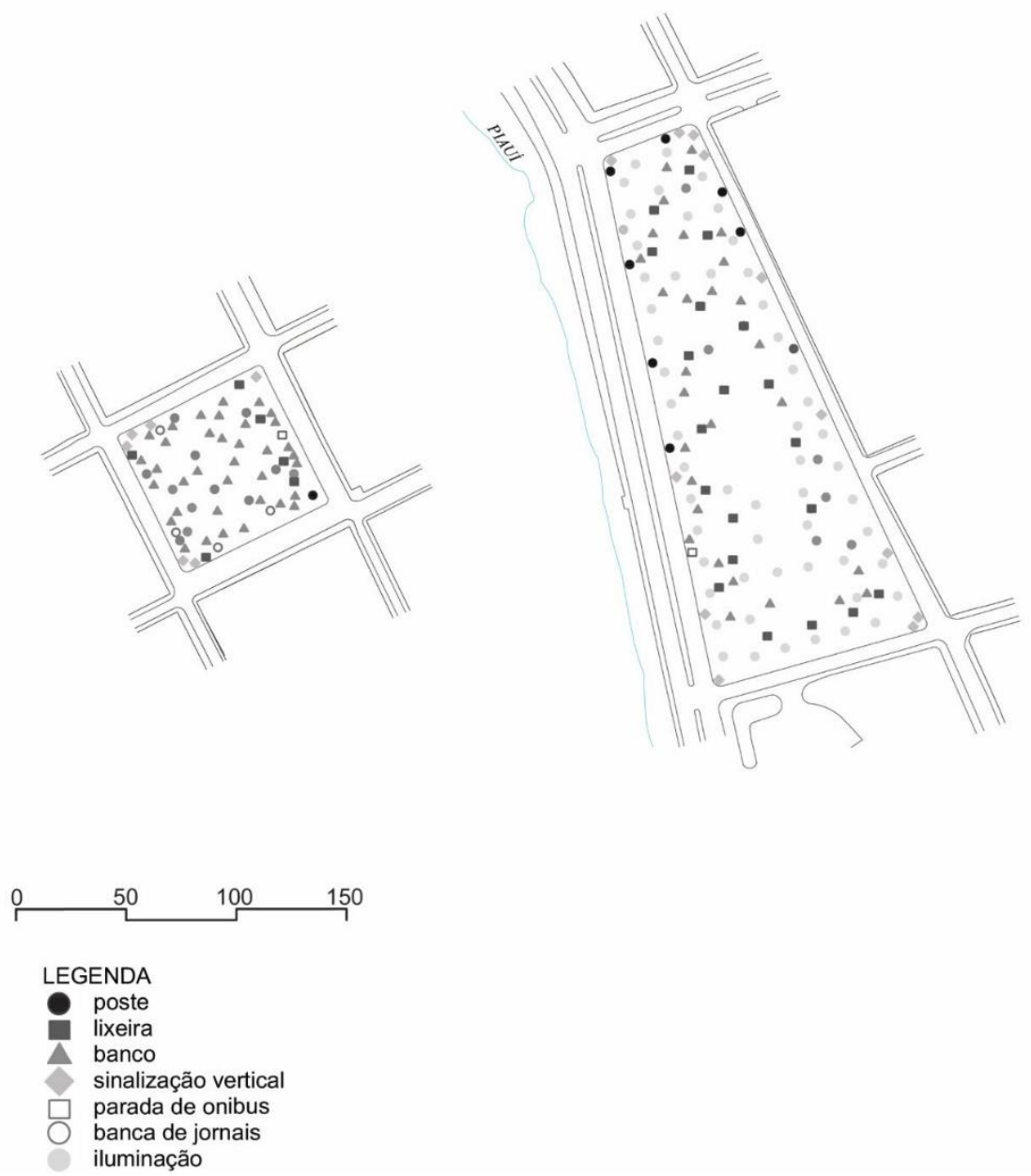

Fig. 12: Cartograma de mobiliário urbano das praças João Luís Ferreira (à esquerda) e Da Costa e Silva (à direita). Fonte: Elaboração própria. 


\section{XII $\quad$ SÃOPAULO15 $17 \cdot$ LISBOA $25 \sim 26$ JUN 2020}

\subsection{Discussões quanto à Apropriação dos Espaços}

Foi observado, nas visitas às praças, que a Praça João Luís Ferreira apresenta apropriação de espaço muito maior em comparação à Praça Da Costa e Silva. Entende-se que a apropriação do espaço urbano diz respeito, em suma, ao uso deste espaço por seus usuários: o desenvolvimento de atividades, a recorrência de percursos, ainda que breves. Um espaço urbano que possui atividades fixas e estacionárias (presença de quiosques, pontos de táxi, bancas de revistas), as quais promovem a manutenção do fluxo de pessoas, é um espaço apropriado, dotado de vitalidade.

É comum estimar-se que indicadores como Arborização, Sombreamento, Poluição Sonora e Presença de Mobiliário Urbano tenham maior influência sobre a apropriação dos espaços públicos pela população, por serem diretamente relacionados ao conforto dos usuários. Porém, após a análise, verificou-se que os indicadores de Atividades do Entorno, Atividades Estacionárias, Acessos e Fechamentos prevalecem sobre os demais no que diz respeito à relação com a apropriação do espaço.

No caso da Praça Da Costa e Silva, aspectos como o gradeamento e a existência de poucos acessos contribuem ao baixo fluxo interno de pessoas que, aliados ao silêncio característico desta praça, atribuem uma sensação de insegurança ao equipamento e ao entorno, situação observada determinante para a baixa apropriação. Já a variedade de usos no entorno e a ausência de fechamentos (grades) da Praça João Luís Ferreira, aliada à presença de uma estação de transporte coletivo, contribui ao fluxo de pessoas, instalação de serviços e comércio. Esta interação é fator determinante para a apropriação da praça. Por outro lado, o entorno predominantemente comercial tem impactos sobre a periodicidade da apropriação, majoritariamente diurna em decorrência do horário de funcionamento dos comércios.

No caso da Praça Da Costa e Silva, a irregularidade de edificações e, consequentemente, de usos, junto à natureza dos usos mais abrangentes em área e aos fechamentos (grades) do espaço, ainda que existindo outros indicadores favoráveis à apropriação, se constituem limitantes a este aspecto. Analisando a arborização e qualidade do mobiliário urbano presente, as praças são espaços com potencial para atração de pessoas frente às características interpretadas satisfatórias. Entretanto, quando analisadas junto aos outros indicadores, estas questões, ainda que positivas, têm menor influência na apropriação dos espaços. Por haver poucas atividades que proporcionam alto fluxo de pedestres próximas à Praça Da Costa e Silva, a população pouco é atraída a este espaço. A praça João Luís Ferreira, no entanto, possui variedade de atividades, contribuindo a um cenário oposto.

Além disso, tem-se o descaso com a imagem que a praça Da Costa e Silva adquiriu com o decorrer do tempo, associados à falta de segurança e à marginalização do entorno da praça, surgindo problemas que prejudicam a circulação de pessoas nesse espaço, contribuindo para a baixa apropriação.

\section{Considerações Finais}

Grande parte das cidades sofre com problemas oriundos do planejamento urbano inadequado, afetando, entre outros aspectos, os espaços livres de convivência. Estes são essenciais ao alcance da sustentabilidade urbana pois, quando bem planejados, qualificam a paisagem, colaboraram para a manutenção dos serviços ecossistêmicos em meio urbano, agregam qualidade ambiental urbana, qualidade de vida e contribuem para a apropriação pela população. 


\section{SÃOPAULO15 $17 \cdot$ LISBOA $25 \sim 26$ JUN 2020}

Essas questões estão relacionadas a aspectos que podem ser avaliados a partir de indicadores de qualidade ambiental urbana, como exposto. Esses indicadores são importantes por contribuírem para a análise das implicações dos aspectos físico-ambientais da forma urbana, além de possibilitarem a compreensão de particularidades dos contextos analisados. As análises realizadas neste trabalho buscaram correlacionar 0 grau de influência dos aspectos da forma urbana às características de apropriação de duas praças do Centro de Teresina.

Pretendeu-se discutir relações entre os aspectos físico-ambientais das praças que contribuem à apropriação, concluindo que aspectos relativos ao espaço e ao seu entorno que atraem usuários possuem maior contribuição à apropriação espacial que aspectos comumente tidos como propiciadores de conforto ambiental. Por exemplo, um entorno com atividades comerciais e de serviços, ou a existência de um terminal de passageiros são potenciais indutores de fluxos e de uso do espaço, e contribuem para a apropriação do espaço em maior grau que aspectos como vasta arborização, atrativos paisagísticos e mobiliário urbano conservado, como observado nas praças analisadas.

As análises mostram que as características do desenho do espaço público são importantes para o uso do espaço, mas que tão importante quanto, ou mais, é o planejamento do uso do solo no entorno, o qual tem larga influência na apropriação. Como evidenciado, a Praça Da Costa e Silva denota um conjunto mais favorável de indicadores de conforto, em relação à Praça João Luís Ferreira; porém, a falta de variedade de usos do solo que atraem fluxo de pessoas implica a menor apropriação deste espaço que o da Praça João Luís Ferreira.

No âmbito do projeto e do planejamento de espaços públicos urbanos, a discussão apresentada destaca a importância do pensamento conjunto entre o desenho e o uso do solo, do espaço e do entorno, uma vez que o programa de necessidades do desenho do espaço, por si só, pode não vir a ser suficiente à apropriação deste espaço pelos possíveis usuários, não havendo o alcance de todo o potencial de qualidade ambiental urbana naquele espaço.

\section{Bibliografia}

ACSELRAD, H. (2001). A duração das cidades: sustentabilidade e risco nas políticas urbanas. Rio de Janeiro: Lamparina.

AGUIAR, D. (2012). Urbanidade e a qualidade da cidade. Em: AGUIAR, D., NETTO, V. M. (orgs.) Urbanidades (61-79). Rio de Janeiro: Folio Digital.

JACOBS, J. (2000). Morte e Vida das Grandes Cidades. São Paulo: Editora Martins Fontes.

KOHLSDORF, M. E. (1996). A Apreensão da Forma da Cidade. Brasília: Editora da UnB.

LIMA, V. \& AMORIM, M. C. C. T. (2006) A importância das Áreas Verdes para a Qualidade Ambiental das cidades. Revista Formação, 13, 139-165. Disponível em: http://revista.fct.unesp.br/index.php/formacao/article/viewFile/835/849Val (consulta: 04 /07/2019).

LODOBA, C. R. \& ANGELIS, B. L. D. (2005). Áreas públicas urbanas: conceitos, usos e funções. Revista Ambiência (Guarapuava, PR), 1 (1), 125-139. Disponível em: http://revistas.unicentro.br/index.php/ambiencia/article/viewFile/157/185 (consulta: 26/03/2019). 


\section{SÃO PAULO15 17 LISBOA $25 \sim 26$ JUN 2020}

LOMBARDO, M. A. (1985). Ilha de Calor nas Metrópoles: o exemplo de São Paulo. São Paulo: Hucitec.

MACEDO, S. S., QUEIROGA, E. F., GALENDER, F. C., CAMPOS, A. C.A., CUSTÓDIO, V., DEGREAS, H., GONÇALVES, F. M. (2012). Os Sistemas de Espaços Livres na constituição da forma urbana contemporânea no Brasil: produção e apropriação (QUAPÁ-SEL II). Paisagem Ambiente (São Paulo), 30, 137-172. Disponível em: http://www.revistas.usp.br/paam/article/view/78112/82200 (consulta: 26/04/2019).

MAGNOLI, M. M. (2006). O parque no desenho urbano. Paisagem Ambiente (São Paulo), Especial Miranda Magnoli, 21, 143-213.

MARTINS, M. F., CÂNDIDO, G. A. (2013). Análise da sustentabilidade urbana no contexto das cidades: proposição de critérios e indicadores. XXXVII Encontro da ANPAD - Associação Nacional de pós-graduação e pesquisa em Administração, Rio de Janeiro (em papel).

MASCARÓ, L. E., MASCARÓ, J. L. (2002). Vegetação urbana. Porto Alegre: UFRGS : FINEP.

MIRANDA, M. M. S. (2015). O Papel dos Parques Urbanos no Sistema de Espaços Livres de Porto Alegre: Uso, forma e apropriação [Tese de Doutorado em Arquitetura, Universidade Federal do Rio de Janeiro].

RATTNER, H. (2009). Prefácio. Em: ACSELRAD, H. A duração das cidades: sustentabilidade e risco nas políticas urbanas (7-18). Rio de Janeiro: Lamparina.

RODRIGUES, F. M. (1986). Desenho Urbano: cabeça, campo e prancheta. São Paulo: Projeto.

SANTOS, C. R. \& HARDT, L. P. A. (2013). Qualidade Ambiental e de Vida nas Cidades. Em: GONZALES, S., FRANCISCONI, J. G., PAVIANI, A. (orgs.). Planejamento e Urbanismo na Atualidade Brasileira. Objeto, teoria, prática (151-168). Rio de Janeiro: Livre Expressão.

SCHLEE, M. B., NUNES, M. J., REGO, A. Q., RHEINGANTZ, P., DIAS, M. A., TÂNGARI, V. R. (2009). Sistema de Espaços Livres nas Cidades Brasileiras - um debate conceitual. Paisagem Ambiente (São Paulo), 26, 225-247. Disponível em: http://www.revistas.usp.br/paam/article/view/77358/81206 (consulta: 03/04/2019).

SEWELL, G. H. (1978). Administração e controle da qualidade ambiental. São Paulo: EDUSP : CETESB.

SWYNGEDOUW, E. (2009). A cidade como um híbrido: natureza, sociedade e "urbanização ciborgue" (99120). Em: ACSELRAD, H. A duração das cidades: sustentabilidade e risco nas políticas urbanas. Rio de Janeiro: Lamparina. 